\title{
Role of Practical Teaching in Cultivation of Civil Engineering Talents
}

\author{
Yan Liu ${ }^{1}$, Xiyuan Sun ${ }^{2}$, Weimin Yin ${ }^{1}$, Zhengyin Zhang ${ }^{1}$, Bingquan Tang ${ }^{1}$ \\ (1 School of Construction Science and Engineering, Yangzhou University, Yangzhou, Jiangsu, \\ 225127)
}

(2 Jiangsu WoEasy Software Co., Ltd., Yancheng, Jiangsu, 224005)

Key words: practical teaching, civil engineering, talent cultivation, new mode

\begin{abstract}
: construction \& production practice is very critical to the cultivation of civil engineering talents. Firstly, the paper discusses the importance of practice, and believes that to integrate understanding the world and reforming the world, and to combine theoretical knowledge with professional practice, thus to fully grasp the knowledge that we have learned, we have to adhere to practice-based view, respect objective laws, and bring our subjective initiative into play. The paper also introduces a new practice mode under the background of big data, which aims to utilize civil engineering practice platform to improve innovative ability of students. Through the new practice mode, educators are allowed to further give full play to the role of practical teaching and improve the effectiveness of the practice-based educating activities.
\end{abstract}

\section{Introduction}

It is a scientific practice viewpoint that understanding the world and reforming the world should be integrated into a whole. Marxist philosophy holds that practice itself is objective a material activity of human beings for reforming the world dynamically, and is regarded as a fundamental way for changing the world and changing the reality. Without practice, changing the world or changing reality is empty talk. Meanwhile, practice is the driving source and power of cognition; it is not only the sole criterion for testing truthfulness of recognition, and also the fundamental way of recognizing the world. Civil engineering is a very practical subject, and only through adhering to practice-based view, respecting objective laws, and bringing our subjective initiative into play, can we integrate understanding the world and reforming the world, and combine theoretical knowledge with professional practice, thus to fully grasp the knowledge that we have learned.

\section{Importance of practical teaching}

It is believed under the principle of material unity of the world every material substance is changing and moving, and every material substance originates from changing and moving material. Therefore, people who pursue success in practice shall pay attention to the objective world and its regularity, and follow the principle of proceeding from reality and seeking truth from facts. Otherwise, we are bound to fail in practice ${ }^{[1]}$.

"Reality" is extremely complex. To fully learn about existence of complexity, it is required to understand objective objects and objective facts, and gain the ability to analyze these objects and facts by using materialist dialectics, including their phenomenon and essence, form and content, locality and globality, mainstream and branches, chance and necessity, possibility and reality, thereby firmly gaining the essence, content, globality, necessity and trend.

Subjectivism is opposite to the principle of proceeding from reality. The basic characteristics of subjectivism are dualism between the subjective and the objective, as well as disconnection between theory and practice. It goes against substance-primary and consciousness-secondary materialist worldview, but it is idealism as manifested in actual work and thinking.

Therefore, civil engineering students are required to balance the relationship between the subjective (self-cognition) and the objective (construction site), as well as that between theory and practice in practical work and life. If one fails to proceed from the objective reality, but from the subjective judgment and intent, or textbooks, her/his knowledge will conflict with practical work, 
resulting in subjective and objective discrepancy, disconnection between theory and practice, and failure in practical teaching activities. Subjectivism is greatly harmful. Mao Zedong pointed out that those subjectivists never make thorough and systemic research on the surrounding environment, but blindly work with subjective enthusiasm, ignore the existence of objective reality. As he once said: subjectivists are like reeds on the wall, with heavy top part, light bottom and short roots, or like bamboo shoots in mountain, with sharp tongue, thick skin but empty belly.

Subjectivism can be reflected in many ways in the actual work: empirical subjectivists guide work with typical experience, without distinguishing between universality and special form of expression, but apply mechanically and simply. Voluntarist subjectivists neither conscientiously study theory, nor pay attention to investigation on actual situation, but take personal feelings as policies with subjective enthusiasm. In order to overcome subjectivism, it is needed to proceed from reality, find proper remedies for the above cases of subjectivism, without ignoring the harm of any form of subjectivism, and at the same time, we should avoid jumping from one form of subjectivism into another during the remedying process. Civil engineering students shall be alert to subjectivism, actively participate in civil engineering practical teaching activities, thus combine theory with practice, and further upgrade theoretical knowledge during practical teaching activities.

\section{Sublimation and consolidation of knowledge in practice}

Firstly, practice is regarded as the source of recognition. People learn about phenomenon of objects through the sense-based experience in practice, further recognize nature of objects through phenomena, thereby to understand the regularity of objects. Human perceptual intuition is only capable of reflecting phenomena, namely external relations of objects. It is impossible to understand the laws of objects and guide practice with such knowledge unless changing objects in a practical way, and exposing their internal links and laws. The essence and laws of objects can be gained by human thinking, but social practice is just regarded as the most essential and the closest basis of human thinking. Of course, the viewpoint that practice acts as the source of recognition does not exclude the need for acceptance of indirect knowledge. The above view is based on the overall human perception. Each specific subject mainly obtains experience from her/his indirect knowledge. Utilizing direct experience is unnecessary and impossible in dealing with everything. Therefore, all cognition of human comes from practice.

Secondly, practice is the driving force of cognitive development. The needs for practice can promote emergence and development of cognition, promote human scientific discovery and technological invention, and promote progressive ideas and theoretical innovation. It is analyzed from the cognition process that cognition arises from needs for practices. Needs for practice is very critical to determining which objects will, from which aspects and levels, be cognized in complex external environment, and further become the cognitive object. According to Engels, once society has technical need, such need will generate a stronger driving force than scientific research in ten universities. Practice not only generates cognition needs, but also continuously provides conditions and tools for development of cognition, including empirical data, laboratory equipment and tools. In addition, practice plays a bridging role for direct interaction between subject and object, and is capable of helping subject to obtain the most real, and the most reliable first-hand information about the object, thus enabling the subject to reflect the object fully and accurately.

Moreover, practice is the purpose of cogitation. Marxist philosophy holds that the most important issue is to change the world by applying knowledge actively, rather than to cognize the laws of the objective world and further explain the world. That is to say, the purpose of understanding the world is to change the world. Cognizing activities are actually a dynamic process for realizing practical purposes; in this process, deepening cognitive level and changes in form of cognition are subject to needs of practice development, namely, some of people's needs for production and living. Thus, the ultimate goal of cognition is to guide practice, namely to guide the practical work with knowledge that has been formed, and to promote the sound development of practice. Only practical work achievements can reflect the value of cognition. 


\section{Respect objective laws, and actively participate in practice}

Fundamentally speaking, the point of view of proceeding from practice in all work requires us to respect and grasp the objective laws. This requires us to give full play to the initiative, recognize the objective law in practice, and actively change the world by utilizing such laws. Scientific theory is a reflection of external world in human consciousness, and a reflection of essence of nature, society and thinking movement in human mind. It aims to show and present the understanding of the objective laws by conceptual logical system. Learning and application of scientific theory is not only the premise for gaining objective laws, and also the prerequisite for utilizing people's initiative. In real life and practical work, utilizing people's initiative has two different views, the right one and the wrong one. It is required to prevent two tendencies in relations between initiatives and objective laws: the first is to exaggerate the role of subjective initiative, ignore the objective laws, and blindly work with subjective imagination and passion, thus to exceed the permitted range of objective possibility to perform some impossible tasks; the second tendency is that subjective guide is outdated compared with the development of objective situation, and that people work in a negative and pessimistic manner, refuse to make subjective efforts to outcome and fight. Such view lags behind the development of objective situation, and it is a conservative ideology that may miss opportunities, and omit subjective initiative during the process of understanding and practice, which also deviates from Marxist philosophy. During the practice process of civil engineering, the two wrong tendencies should be prevented.

Investigation is the core factor of proceeding from the reality, and a typical form for respecting the objective laws, and utilizing subjective initiative. Investigation is regarded as a specific embodiment of the materialist understanding route "object - sense - thought", and a specific way of utilizing subjective initiative and mastering objective laws, therefore it is the fundamental method for proceeding from reality in all work.

It is analyzed from human cognitive activities that investigation is the upgrading process from perceptual knowledge to rational knowledge, and from phenomena to law and essence. In investigation, the results are utterly different as the stand, viewpoint and methods vary. Therefore, civil engineering students shall actively carry out research and investigation under the guidance of the site engineers, learn to apply what they have learned to analyzing and solving problems that arise during practice.

\section{New teaching mode under big data background}

In order to enhance professional practice, the Ministry of Education issued "Several Opinions by the Ministry of Education and Other Departments on Further Strengthening Practical Education in Colleges and Universities” in February 2012 and the document clearly requires strengthening practical teaching. Practical teaching is considered an important part of teaching work and an important aspect of upgrading classroom teaching, as well as an important way for obtaining and mastering knowledge. All colleges and universities shall classify and formulate practical teaching standards, increase the proportion of practical teaching activities, in conjunction with professional features and personnel training requirements; it is also required that the reform in practical teaching method is critical to promoting practical teaching reform and personnel training mode reform. Colleges and universities should further strengthen the reform in practical teaching method in professional subject development, focus on implementation of problem-based, project-based, case-based teaching methods and learning methods, as well as strengthen design and application of the comprehensive practical subjects ${ }^{[2]}$.

Currently, the world has entered into the era of big data; with the development of Internet technology, wechat can be widely used as a client terminal. The close combination of wechat \& big data with civil engineering practice is a new model of civil engineering practice. To this end, Yangzhou University, Nanjing WoEasy Software and Yancheng Institute of Technology jointly developed the "Zanxue" civil engineering practice real-time sharing platform. The platform allows each person to share practice information in real-time on the Internet through personal APP mobile 
terminals. By integrating big data platform, students are allowed to achieve online sharing, communication and learning, and teachers can also provide real-time guidance, reviews and ratings through the Internet.

The platform not only makes teachers' long-distance supervision easier, and also mobilizes students in practice, enhances the interaction between teachers and students, as well as between students; students' information contains text and images, introduces practical activities on construction site for real-time sharing, and the platform also supports followers to give comments. Meanwhile, the big data platform is capable of quantifying each student's practice via scoring system, ranking their places to stimulate their driving force in practice and learning. The construction site is moved into the Internet, therefore during practices students are allowed to cognize engineering, experience construction, gain experience, and broaden their horizons, thus to improve professional quality and expertise. The internship platform has been applied in construction and production practice over past two years. Compared with traditional ways, students submit more diversified diary reports and significantly reduce plagiarism; students spend more time on practice at the site, and improve the effectiveness of internship significantly. Through practice, they further optimize the understanding and application of theoretical knowledge ${ }^{[3]}$.

\section{Conclusions}

This route, "practice, cognition, re-practice, and recognition", repeats itself endlessly, and the content in each step of practice and cognition can be further upgraded to a higher level.” This is dialectical movement \& development process of cognition. In this process, cognition is continuously deepening and developing in a scientific manner, on the basis of practice, and practice is further optimized and rationalized under the guidance of cognition. Of course, this process is not linear, but it is often full of twists and turns as well as repetitions, therefore it is a wave-like forward and spiraling process. In practical work, educators should pay attention to constant practice and exploration, summarize experience continuously, and form correct understanding, thus to guide professional practice more effectively. Civil engineering students shall establish a correct concept of practice, keep learning theory, combine innovative thinking with professional practice, learn from practice and mass people, and cultivate the spirit of innovation in exploring and practice, as well as the ability to solve problems, thus to grow gradually into qualified builders and reliable successors for the socialist cause of China.

\section{Acknowledgments}

The authors would like to express sincere thanks to Education Department of Jiangsu province and Yangzhou University. This research was funded from Higher education teaching reform research project in Jiangsu province in 2015(Grant No. 2015JSJG064) and Yangzhou university educational reform projects of 2015(Grant No. YZUJX2015—5A).

\section{References}

[1] The Theory Bureau of Propaganda Department of the CPC Central Committee; Marxist Philosophy Ten Lectures, Beijing: Party Building Readings Press, 2013.

[2] Document by Ministry of Education. Several Opinions by the Ministry of Education and other departments on further strengthening practical education in colleges and universities; Ministry of Education, People's Republic of China, Feb. 2012

[3] http://www.pgyer.com/zanxuewangs 